\author{
Contato \\ Universidade de São Paulo \\ Faculdade de Economia, Administração e Contabilidade \\ Departamento de Economia \\ Av. Prof. Luciano Gualberto, 908 \\ 05508-010 - São Paulo - SP - Brasil \\ carla.sasse@gmail.com \\ alexandre.saes@usp.br
}

\section{A ELETROBRAS \\ E AS EMPRESAS FORNECEDORAS DE EQUIPAMENTOS PARA O SETOR ELÉTRICO BRASILEIRO (1960-1980)}

\section{Carla Muller Sasse*}

Universidade de São Paulo São Paulo - São Paulo - Brasil

\section{Alexandre Macchione Saes**}

Universidade de São Paulo

São Paulo - São Paulo - Brasil

\title{
Resumo
}

O artigo avalia a formação do setor de bens de capital sob encomenda para o setor elétrico como parte de um novo ciclo de investimento fomentado pelo Estado brasileiro entre as décadas de 1960 e 1970. Para tanto, tomamos como base os dados da principal consumidora individual de equipamentos elétricos naquele momento, a Eletrobras. O artigo analisa o perfil dos equipamentos elétricos mais custosos usados pela Eletrobras em seus projetos hidrelétricos, o que confirma a ideia de que a política econômica dos governos no período foi decisiva para a definição dos fornecedores e, por isso, para criar as possibilidades de desenvolvimento da indústria nacional.

\section{Palavras-chave}

Energia elétrica - bens de capital - Eletrobras.

* Mestre pelo Programa de Pós-Graduação em História Econômica da Faculdade de Filosofia, Letras e Ciências Humanas.

** Professor doutor no Departamento de Economia, da Faculdade de Economia, Administração e Contabilidade e do Programa de Pós-Graduação em História Econômica da Faculdade de Filosofia, Letras e Ciências Humanas. Bolsista do Conselho Nacional de Desenvolvimento Científico e Tecnológico - CNPq. 


\section{Contact \\ Universidade de São Paulo Faculdade de Economia, Administração e Contabilidade \\ Departamento de Economia Av. Prof. Luciano Gualberto, 908 05508-010 - São Paulo - SP - Brasil carla.sasse@gmail.com alexandre.saes@usp.br}

\section{ELETROBRAS AND THE EQUIPMENT SUPPLIERS FOR THE BRAZILIAN ELECTRICITY SECTOR (1960 TO 1980)}

\section{Carla Muller Sasse}

Universidade de São Paulo

São Paulo - São Paulo - Brasil

Alexandre Macchione Saes

Universidade de São Paulo

São Paulo - São Paulo - Brasil

\begin{abstract}
The article evaluates the formation of the custom capital goods for the electricity sector as part of a new investment cycle encouraged by the Brazilian state between 1960 and 1970. To this end we make use of the data of the largest consumer of electrical equipment at that time, the company Eletrobras. The article analyzes the profile of the most expensive electrical equipment used by Eletrobras in its hydroelectric projects, confirmating the idea that the economic policy of governments in that period was decisive for the definition of suppliers and therefore to create the national industry development possibilities.
\end{abstract}

\title{
Keywords
}

Electric power - capital goods - Eletrobras. 


\section{Introdução}

A disseminação da eletricidade, tanto para iluminação pública e privada das cidades quanto como força motriz para fins de transporte ou de produção industrial, foi um dos grandes motores de crescimento econômico mundial do século XX. Na periferia, em países como o Brasil, é possível destacar dois grupos de empresas privadas que atuaram no setor em períodos distintos: até meados do século XX, a disseminação de eletricidade pelo país tornou a atividade de fornecimento de energia, por meio de empresas de serviços públicos, um atrativo negócio para o capital privado. ${ }^{1}$ Sendo a produção de materiais elétricos ainda fenômeno exógeno, o papel das empresas fabricantes de materiais elétricos no país era basicamente o de suprir equipamentos tecnologicamente mais simples, o que representava pouco no custo dos investimentos dos sistemas elétricos. A partir da segunda metade do século, entretanto, com o aprofundamento das políticas de industrialização por substituição de importação e a disseminação de investimento direto estrangeiro dos países centrais, os investimentos nas companhias de serviços públicos passaram a ser menos priorizados em detrimento da criação de indústrias de bens de capital na periferia.

Esse processo tornou-se evidente na década de 1950, que marcou o período de inflexão no fornecimento de serviços do setor elétrico brasileiro, resultado da crescente atuação do governo, seja por meio de empreendimentos federais, seja por meio da atuação de empresas estaduais na oferta dos serviços. Em pouco mais de uma década (1952-1965), a participação das empresas públicas na geração de energia saltou de cerca de 7\% para quase 55\%. Essa alteração era decorrente de uma nova perspectiva do governo, que passou a priorizar o setor e encarar a oferta de energia elétrica como estratégica para o crescimento econômico e para o desenvolvimento industrial do país. Mas o aumento da participação do Estado também resultou do estrangulamento da rentabilidade dos negócios para as empresas privadas, assim como da maior regulação estatal, do processo inflacionário do pós-guerra e dos crescentes custos que os investimentos em geração exigiam. Essa tendência de alteração do papel dos personagens no setor elétrico brasileiro, especialmen-

\footnotetext{
1 Para a presença dos grupos privados nacionais, ver: SAES, Flávio. A grande empresa de serviços públicos na economia cafeeira. São Paulo: Hucitec, 1986; para o controle dos grupos estrangeiros dos maiores mercados brasileiros, ver: MARTIN, Jean-Marie. Processus d'industrialisation et développement énergétique du Brésil. Paris: Institut des Hautes Études de l'Amérique Latine, 1966.
} 
te na geração de energia, seguia tardiamente as experiências internacionais da chamada domesticação do setor. ${ }^{2}$

O esgotamento do ciclo de investimento privado na atuação dos serviços já foi bastante retratado na literatura. Na mais recente síntese sobre a evolução do setor elétrico mundial, o trabalho de Hausman, Hertner e Wilkins (2008), essa alteração nos atores responsáveis pelo setor elétrico aparece como ondas de nacionalização ou internacionalização das empresas de serviços públicos. O pós-Segunda Guerra Mundial reforçou a tendência de nacionalização do setor na América Latina, com desafio bastante semelhante nos países da região, como é possível observar na literatura das experiências do Brasil e da Argentina. ${ }^{3}$ No caso específico do Brasil, são consideráveis os estudos que se voltaram para analisar os debates sobre a nacionalização dos serviços travados durante os anos 1950, do desenrolar do projeto de criação da Eletrobras e das acusações entre privatistas e estatistas sobre o setor. ${ }^{4}$

Mais importante para nosso objeto de estudo - a organização da indústria de bens de capital sob encomenda para o setor elétrico entre os anos 1960 e 1980 - são aqueles estudos que indicam os limites do ciclo de investimento do setor de serviços públicos em meados do século XX, reforçando o direcionamento do capital estrangeiro para novas atividades. Nivalde Castro, ainda com um olhar exclusivo no setor de serviços públicos, chamou esse processo de "pacto de clivagem", indicando a fratura do setor elétrico entre a geração, a transmissão e a distribuição de energia, e considerando que o setor privado teria ficado com a fatia mais rentável da divisão, a distribuição

2 CLIFTON, Judith; LANTHIER, Pierre; SCHRÖTER, Harm. Regulating and deregulating the public utilities, 1830-2010. Business History, 53 (5), 2011, p. 659-672; HAUSMAN, William; HERTNER, Peter; WILKINS, Mira. Global electrification. Multinational enterprise and international finance in the history of Light and Power, 1878-2007. Cambridge: Cambridge University Press, 2008.

3 LANCIOTTI, Norma \& SAES, Alexandre. La regulación de los servicios de electricidad en Argentina y Brasil (1890 e 1962). Economia e Sociedade. 21, 2012. Para a trajetória das empresas privadas na Argentina, ver: LANCIOTTI, Norma. Ciclos de vida en empresas de servicios públicos. Las companies eléctricas británicas y norteamericanas en Argentina, 1887-1950, Revista de Historia Económica- Journal of Iberian and Latin American Economic History, XXVI: 3, 2008 e LANCIOTTI, Norma. Foreign investments in electric utilities: A comparative analysis of Belgian and American Companies in Argentina, 1890-1959, Business History Review, 82 (3), 2008.

4 Apenas para apontar alguns importantes exemplos: BRANCO, Catullo. Energia elétrica e capital estrangeiro no Brasil. São Paulo: Alfa-Ômega, 1975; LIMA, José Luiz. Estado e energia elétrica no Brasil. São Paulo: IPE/USP, 1984; ALMEIDA, Marcio Wohlers de. Estado e energia elétrica em São Paulo: Cesp, um estudo de caso. Campinas: Dissertação de mestrado - IFCH-UNICAMP, 1980; MARANHÃO, Ricardo. Capital estrangeiro e estado na eletrificação brasileira: A Light, 1945-1957. Tese de doutoramento FFLCH/USP, São Paulo, 1993. 
de eletricidade, deixando como legado a geração e a transmissão às empresas públicas em formação. Judith Tendler, por sua vez, aponta essa tendência de especialização das empresas privadas na distribuição de energia elétrica como consequência da inflação e do controle de preços realizado pelos governos no período do pós-guerra, que gerou crescente desinteresse do capital estrangeiro para novos investimentos em geração durante a década de $1950 .^{6}$

O transbordamento do capital das empresas elétricas para novas atividades pode ter sido outro percurso usado como estratagema pelos grupos privados. Afinal, mesmo a atividade de distribuição parece não ter se mantido como nuclear nos investimentos privados a partir dos anos 1950, especialmente aqueles investimentos realizados por empresas estrangeiras. ${ }^{7}$ O caso da American Foreign Power (AFE'P) é significativo nesse sentido, pois sua encampação realizada entre o governo João Goulart e o início do governo militar, diferente de como foi tratada na literatura, é muito mais o resultado do desinteresse dos empresários americanos pela manutenção da empresa no Brasil do que uma vitória das forças nacionalistas. ${ }^{8}$ A saída da AFEP do Brasil ocorreu simultaneamente ao estabelecimento de uma importante fábrica de sua holding company no país, a General Eletric, o que pode indicar nova dimensão dos investimentos que partiam do setor de serviços para o industrial. Outro estudo esclarecedor é o de Odette Seabra sobre a presença da companhia canadense Light na cidade de São Paulo. Segundo a autora, as intervenções da empresa na cidade de São Paulo, sobretudo no que diz respeito às obras de retificação dos rios Tietê e Pinheiros, permitiram que a Light assumisse, por meio de desapropriações, enorme quantidade de

5 CASTRO, Nivaldo. O setor de energia elétrica no Brasil: a transição da propriedade privada para a propriedade pública, 1945-1961. Dissertação de mestrado, UFRJ, Rio de Janeiro, 1985.

6 TENDLER, Judith. Electric power in Brazil: Entrepreneurship in the public sector. Cambridge: Harvard University Press, 1968.

7 Cabe reforçar que os investimentos no setor de serviços elétricos movimentaram uma quantidade de capital que não é desprezível: a Light era, em meados do século XX, a maior empresa canadense no exterior, assim como a norte-americana American Foreign Power tinha sido a maior dos Estados Unidos nos anos 1930. Para a Light, ver: McDOWALL, Duncan. The Light: Brazilian Traction, Light and Power Company Limited, 1899-1945. Toronto: University of Toronto Press, 1988. Para AFEP, ver: WILKINS, Mira. The history of foreign investment in the United States, 1914-1945. Cambridge, MA: Harvard University Press, 2004.

${ }^{8}$ Cf: SAES, Alexandre $\mathcal{E}$ LOUREIRO, Felipe. What developing countries' past energy policies can tell us about energy issues today? Lessons from the expropriation of American Foreign and Power in Brazil (1959-1965). Utilities Policy, v. 29, 2014, p. 36-43. 
terras na cidade. ${ }^{9}$ É sugestivo pensar que das entranhas da companhia canadense seria formada, em 1958, a Brascan Imobiliária, empresa voltada para os empreendimentos imobiliários, justamente quando a participação da Light no setor elétrico paulista se encerrava.

O argumento do artigo é, portanto, de que a transição para a década de 1960 marcou uma inflexão na atuação do capital estrangeiro no setor elétrico. Se no caso de algumas empresas é possível observar esse deslocamento de atuação do setor de serviços públicos para o industrial ou imobiliário, no que diz respeito à formação da indústria de bens de capital sob encomenda para o setor elétrico brasileiro, de maneira geral, não é possível dissociar sua expansão como reflexo de uma nova perspectiva do capital estrangeiro sobre o mercado numa periferia em industrialização, como também dos incentivos criados pelo governo para atrair esse perfil de indústria para a economia brasileira.

Na literatura encontramos importantes obras sobre a temática da indústria de bens de capital no Brasil entre as décadas de 1960 e 1970. Notadamente esses estudos refletem o expressivo desempenho do setor de bens de capital na economia brasileira encontrado entre o Plano de Metas e o Milagre Econômico brasileiro, que, ao ampliar sua participação no total da produção nacional, teria conseguido endogenizar o processo de acumulação. ${ }^{10} \mathrm{Ou}-$ tros trabalhos procuraram compreender a estrutura desse setor, tendo como olhar, por um lado, a política econômica do governo e, de outro, a estrutura empresarial, os mecanismos de financiamento dos grupos e a trajetória dos principais ramos industriais. ${ }^{11}$ Existem estudos mais específicos, como aqueles dedicados à análise da indústria de bens de capital sob encomenda, isto é, das empresas produtoras de máquinas e de equipamento não seriados. Essa

\footnotetext{
9 SEABRA, Odette. Dos meandros dos rios dos meandros do poder. Tese de doutorado - FFLCH/USP, São Paulo, 1987.

${ }^{10}$ Para autores da escola da Unicamp, como Maria da Conceição Tavares e João Manuel Cardoso de Melo, o período de 1956 a 1961 marca o momento de construção da indústria pesada no país, em uma fase em que o processo de substituição de importações alcançava seu limite, mas garantia o fechamento do parque industrial do país. Cf. TAVARES, Maria da Conceição. Auge e declínio do processo de substituição de importações no Brasil. Da substituição de importações ao capitalismo financeiro. Rio de Janeiro: Zahar, 1972 e MELLO, João Manuel Cardoso de. $O$ capitalismo tardio. São Paulo: Brasiliense, 1982.

${ }^{11}$ Cf. LESSA, Carlos. Quinze anos de política econômica. São Paulo: Brasiliense, 1975; LEFF, Nathaniel. The Brazilian capital goods industry; 1929-1964. Cambridge: Harvard University Press, 1968; LAGO, Luís Corrêa do, et al. A indústria brasileira de bens de capital. Rio de Janeiro: IBRE/FGV, 1979 e ERBER, Fabio Stefano. Absorção e criação de tecnologias na indústria de bens de capital. Rio de Janeiro, Financiadora de Estudos e Projetos, 1974.
} 
indústria volta-se para o atendimento dos projetos industriais com demandas particulares, como as hidrelétricas que dependem das condições naturais para a definição das características das turbinas e geradores elétricos. ${ }^{12}$ Por fim, até mesmo o setor dedicado ao estudo da produção de material elétrico possui um estudo próprio, especialmente dedicado à ótica da oferta. ${ }^{13}$

O artigo, por sua vez, ao avaliar o setor de bens de capital voltado para o setor elétrico como parte de um novo ciclo de investimento, pretende associar a expansão das empresas produtoras de equipamentos no Brasil com o ambiente favorável criado pelo governo para esses empreendimentos. Assim, além de nos valermos dos dados sobre a ótica da oferta da produção, pretendemos também demonstrar a importância do governo brasileiro como demandante dos produtos mais sofisticados tecnologicamente do setor, que seriam estimulados a internalizar suas produções. Para o artigo, analisamos os chamados bens de capital sob encomenda para o setor elétrico, adquiridos pelo sistema Eletrobras em seus projetos hidrelétricos das décadas de 1960 e $1970 .{ }^{14}$ Ou seja, buscamos avaliar os equipamentos que compuseram os projetos hidrelétricos da empresa, em especial as turbinas e os geradores que representavam os materiais mais complexos na construção das usinas hidrelétricas. ${ }^{15} \mathrm{O}$ artigo demonstra que os projetos políticos dos governos entre 1960 e 1980 foram decisivos para fomentar o desenvolvimento da indústria de bens de capital no Brasil, tanto por meio de multinacionais como por meio da criação de empresas brasileiras.

\footnotetext{
${ }^{12}$ Para este recorte de produtos, ver: TADINI, Venilton. O setor de bens de capital sob encomenda: análise do desenvolvimento recente (1974/83). São Paulo, IPE/USP, 1986.

${ }^{13}$ KLEIN, Lúcia. A implementação dos grandes projetos governamentais nos setores siderúrgico e hidrelétrico, 1974-79. Relatório de Pesquisa, Finep, 1980; KLEIN, Lúcia. Bens de Capital e o Estado no Brasil: a implantação do programa de eletricidade. X ENCONTRO ANUAL DA ANPOCS, Campos do Jordão, 1986; STRACHMAN, Eduardo. Estrutura de mercado, competitividade e políticas para as indústrias internacional e brasileira de bens de capital sob encomenda para o setor elétrico. Dissertação de mestrado - Instituto de Economia, Unicamp, Campinas, 1992.

${ }^{14}$ A Eletrobras foi fundada em 1962, mas para este trabalho consideramos as usinas que estavam em construção no momento da formação da empresa eque seriam posteriormente incorporadas à estatal.

15 "Em relação às especificidades técnicas, os bens de capital são classificados como: seriados (produzidos em larga escala, de forma padronizada, como máquinas agrícolas, tratores, ônibus e caminhões); e sob encomenda (produzidos segundo características técnicas associadas a determinado processo produtivo, como as prensas utilizadas pelas montadoras de automóveis, os alto-fornos das siderúrgicas, as turbinas das usinas hidrelétricas e as plataformas de petróleo)". ALEM, Ana Cláudia \& PESSOA, Ronaldo Martins. O setor de bens de capital e o desenvolvimento econômico: quais são os desafios? BNDES Setorial. Rio de Janeiro, $\mathrm{n}^{\circ}$ 22, 2005, p.75. Disponível em: $<$ www.bndes.gov.br>. Acesso em: $1^{\circ}$ set. 2013.
} 


\title{
A emergência da indústria de bens de capital do setor elétrico no Brasil
}

\begin{abstract}
Hoje produzimos motores elétricos de até $6.000 \mathrm{HP}$, geradores de $50.000 \mathrm{~kW}$, alternadores, conversores, transformadores, equipamentos autoelétricos, material elétrico e acessórios, equipamentos e aparelhos de rádio e de televisão, numa cabal demonstração da nossa capacidade realizadora. Só no estado de São Paulo estão instaladas mais de 3.000 indústrias de aparelhos elétricos e eletrônicos dando trabalho a cerca de 85.000 operários. As nossas fábricas, distribuídas pelo território paulista, ocupam uma área construída de 1 milhão e meio de metros quadrados e o seu consumo de energia elétrica tem crescido em uma média de 37\% ao ano - quase o dobro da média atribuída aos demais ramos. ${ }^{16}$
\end{abstract}

Em 1962, Manoel da Costa Santos tomava posse da presidência do Sindicato da Indústria de Aparelhos Elétricos, Eletrônicos e Similares do Estado de São Paulo e destacava, em seu discurso, a profunda transformação que essa indústria tinha sofrido nos últimos anos. Ao apresentar dados do consumo de energia das indústrias do setor em comparação com a média dos demais ramos, o presidente do Sindicato reforçava a liderança das indústrias de bens de capital sob encomenda para o setor elétrico no crescimento industrial recente. De fato, a partir do Plano de Metas, instaurado no governo do presidente Juscelino Kubitschek, o setor de energia se tornou prioridade para o governo, recebendo 43\% de todos os investimentos que seriam aplicados entre 1957 e 1961. ${ }^{17}$ Se a meta era alcançar um crescimento anual de produção de energia superior a 10\% ao ano, certamente a demanda de equipamentos

\footnotetext{
${ }^{16}$ Para o detalhamento do setor feito no pronunciamento do discurso de posse do presidente do Sindicato, ver: SANTOS, Manoel da Costa. O paradoxo da situação brasileira, vol. XII. São Paulo: Ciesp/Fiesp, 1962, p. 21. (Coleção O Pensamento da Indústria).

${ }^{17} \mathrm{O}$ gargalo da geração de energia elétrica para garantir condições de crescimento econômico já era bastante retratado desde a década anterior: a Missão Cooke (1942), a Abbink (1948) e a Comissão Mista Brasil-Estados Unidos - CMBEU (1951-53) colocavam a ideia de ampliar a geração de energia elétrica como prioridade. Destes, apenas a CMBEU viabilizou instrumentos para financiamento do setor elétrico, e contemplou projetos voltados para empresas públicas, como a Companhia Hidroelétrica do São Francisco (Chesf), a Companhia Estadual de Energia Elétrica (CEEE), as Centrais Elétricas de Minas Gerais S.A. (Cemig) e as Usinas Elétricas do Paranapanema S.A. (Uselpa) e as duas grandes empresas privadas, a canadense Light e a norte-americana AFEP. Cf.: BASTOS, Paulo. A construção do nacionalismo econômico de Vargas. In: BASTOS, Paulo. \& FONSECA, Pedro. (org.). A era Vargas. São Paulo: Ed. Unesp, 2012 e CASTRO, Nivalde. O setor de energia elétrica no Brasil: a transição da propriedade privada para a propriedade pública, 1945-1961. Dissertação de mestrado - UFRJ, Rio de Janeiro, 1985.
} 
representava um gargalo a ser superado, afinal, a indústria do país fornecia nada além de equipamentos elétricos de uso doméstico, de instalações elétricas e de fios e condutores, enquanto dependia da importação, de maneira geral, de geradores, turbinas e transformadores. ${ }^{18}$

A preocupação de JK, na realidade não era nova. A primeira tentativa de constituir uma indústria de equipamentos elétricos pesado, como iniciativa do Estado, ocorreu ainda durante o primeiro governo Vargas, em 1944, com a criação da Comissão da Indústria de Material Elétrico (Cime), que deveria estudar e promover a implantação da indústria de material elétrico pesado no país. No governo de Eurico Gaspar Dutra, passados dois anos de estudos, a comissão entregou seu relatório, no qual foi recomendada a formação de uma companhia de economia mista com participação do governo brasileiro, de particulares nacionais, de particulares norte-americanos, do Eximbank (como credor) e da Westinghouse Electric Internacional Company. A meta da indústria era tornar-se uma fornecedora de turbinas hidráulicas de até 4.000 HP, geradores e transformadores de até $5.000 \mathrm{kVA}$ e de grandes motores elétricos. O plano não foi efetivado. A Cime voltou à baila em 1952, durante o segundo governo de Vargas, agora como Comissão Executiva de Material Elétrico. A empresa deveria ser integrada ao Plano Nacional de Eletrificação com o objetivo de suprir ao menos cinquenta por cento da demanda nacional de equipamentos elétricos. Esse papel de formação de uma empresa fornecedora de produtos industriais foi mais tarde incorporado ao projeto da Eletrobras e enviado ao Congresso em abril de $1954 .^{19}$

O projeto da Eletrobras, como sabemos, era mais amplo do que a constituição de uma empresa produtora de equipamentos elétricos. O trabalho realizado pela comissão de criação da Eletrobras gerou outros quatro projetos enviados ao Congresso:

Os estudos realizados pela comissão resultaram em quatro projetos de lei: a criação do Imposto Único sobre Energia Elétrica (IUEE); a distribuição da parcela do Imposto Único entre as três esferas do executivo; um plano de planejamento para o setor elétrico chamado Plano Nacional de Eletrificação (PNE); e a criação da Eletrobras. ${ }^{20}$

\footnotetext{
${ }^{18}$ LESSA, Carlos. Quinze anos de política econômica. São Paulo: Brasiliense, 1975, p. 18-19.

${ }^{19}$ CACHAPUZ, Paulo Brandi (coord.). Panorama do setor de energia elétrica no Brasil. Rio de Janeiro: Centro de Memória da Eletricidade no Brasil, 2006, p. 247-249.

${ }^{20}$ ECCARD, Frederico Pinto. A importância da Eletrobras para o desenvolvimento do setor elétrico brasileiro. Rio de Janeiro: Unise/Centro Celso Furtado, 2012, p. 17.
} 
Como uma proposta bastante ampla para o setor, os projetos foram votados separadamente. O Imposto Único foi aprovado, por meio da Lei $\mathrm{n}^{\mathrm{o}} 2.308$, somente em agosto de 1954, depois do suicídio de Getúlio Vargas. O imposto seria gerido pelo Fundo Federal de Eletrificação com controle do BNDE. Os demais projetos seriam temas de acalorados debates no Congresso. O Plano Nacional de Eletrificação, também oriundo dos estudos da Assessoria Econômica de Getúlio Vargas, tinha como base o diagnóstico da incapacidade da iniciativa privada de acompanhar a demanda de energia elétrica no país e, por isso, propunha uma grande ação de coordenação da integração energética nacional e de ator na geração de energia. O Plano não foi aprovado, mas seus estudos foram usados como suporte para a ação do Estado no setor nos anos seguintes. A constituição da Eletrobras como empresa geradora e distribuidora de energia seria aprovada somente quase dez anos depois. ${ }^{21}$ Naquele momento, seu projeto foi combatido pelos chamados privatistas e pelas concessionárias estrangeiras. Mais combatido ainda foi o projeto de produção dos equipamentos necessários para atender o setor elétrico nacional, que criaria um complexo industrial capaz de abastecer a cadeia produtiva do setor end to end. ${ }^{22}$

O jornal $O$ Estado de S.Paulo, de 11 de abril de 1954, trazia informações sobre o envio dos projetos ao Congresso Nacional com a íntegra dos textos e das mensagens enviadas pela presidência da República que justificavam a importância da execução do Plano Nacional de Eletrificação e da criação das Centrais Elétricas Brasileiras S.A. ${ }^{23}$ O Plano, de acordo com a mensagem, deveria ser executado no prazo de dez anos e previa o incremento de mais de três vezes da capacidade instalada na época. ${ }^{24}$ Com relação à indústria de material elétrico, a mensagem destacava a importância de instalar no país um parque industrial responsável pela produção de material elétrico pesado, uma vez que a dependência de importações afetava o balanço de pagamentos:

\footnotetext{
${ }^{21}$ LIMA, José Luiz. Estado e desenvolvimento do setor de energia elétrica: do Código das Águas à crise dos anos 80 - 1934-1984. Rio de Janeiro: Memória da Eletricidade, 1995, p. 63-67.

${ }^{22}$ GONÇALVES. Jr., Dorival. Reestruturação do setor elétrico brasileiro: estratégia de retomada da taxa de acumulação do capital? Dissertação de mestrado em Energia - USP, São Paulo, 2002, p. 104.

${ }^{25}$ Enviado ao Congresso pelo Executivo o Plano Nacional de Eletrificação e da Eletrobras. $O$ Estado de S.Paulo, 11 abr. 1954, p. 8.

${ }^{24}$ De acordo com informações técnicas disponíveis na mensagem veiculada pelo jornal $O$ Estado de S.Paulo. Enviado ao Congresso pelo Executivo o Plano Nacional de Eletrificação e da Eletrobras. O Estado de S.Paulo, 11 abr. 1954, p. 8, A capacidade instalada ao final de execução do planejado passaria de 10 bilhões kWs/hora para 25 bilhões kWs/hora.
} 
Assim, o plano está dependendo da instalação de uma indústria pesada de material elétrico que possa suprir pelo menos cinquenta por cento do material a empregar no primeiro decênio. Acentua o presidente da República a confiança do governo em que a iniciativa privada se lance neste empreendimento, adequadamente assistida. Não obstante, o plano prevê recursos para implantação da indústria, mesmo sob a exclusiva responsabilidade da entidade estatal. (...) Parágrafo Único: Terá a empresa, como encargo fundamental, a execução dos empreendimentos federais, constantes no Plano Nacional de Eletrificação, inclusive a criação de material elétrico, se a iniciativa privada não a realizar com a ajuda autorizada em lei. ${ }^{25}$

Mas a solução para o suprimento de equipamentos seria dada em outra direção.

Se até 1954 personagens como Saturnino Braga defendiam a proteção da iniciativa de uma indústria de equipamentos, ${ }^{26}$ a partir do governo de Juscelino Kubitschek, o cenário se transformou por completo. Ilustrando a nova tônica do governo, em 1956, um dos principais personagens na elaboração do Plano de Metas, Lucas Lopes, já apontava a necessidade de "integrar forças" para responder à demanda de materiais elétricos, indicando a opção pela incorporação do capital privado internacional na produção de bens de capital na economia brasileira. ${ }^{27}$

Assim, para superar os limites do balanço de pagamentos e viabilizar a continuidade do processo de industrialização, a estratégia de desenvolvimento assumido pelo governo de JK foi de estimular a entrada de multinacionais no mercado brasileiro. Nesse sentido, enquanto o Estado fomentava o crescimento econômico mediante investimentos em infraestrutura, a iniciativa privada internacional introduzia por meio de multinacionais as indústrias tecnologicamente mais sofisticadas - reduzindo as pressões da importação de produtos centrais para o desenvolvimento industrial -, os grupos privados nacionais se desenvolviam nas franjas dessas novas indústrias com o fornecimento de equipamentos tecnologicamente mais simples. ${ }^{28}$

${ }^{25}$ Enviado ao Congresso pelo Executivo o Plano Nacional de Eletrificação e da Eletrobras. $O$ Estado de S.Paulo, 11 abr. 1954, p. 8.

${ }^{26}$ Saturnino Braga, relator do projeto de criação da Eletrobras, reforçava a necessidade de proteção da indústria de equipamentos. O momento político. Jornal O Estado de S.Paulo, 30 jun. 1954, p. 3.

${ }^{27} \mathrm{O}$ estado de Minas e o Plano de eletrificação do governo federal. Declarações do Sr. Lucas Lopes sobre a participação do capital estrangeiro neste empreendimento. O Estado S. Paulo, 21 nov. 1956. Geral, p. 5.

${ }^{28}$ Para o conceito de divisão de papéis de atuação entre o Estado, as multinacionais e o capital nacional aplicado no estudo do setor elétrico, ver: EVANS, Peter. A tríplice aliança: as multinacionais, as estatais e o capital nacional no desenvolvimento dependente Brasileiro. Rio de Janeiro, Zahar, 1980. Ver 
Para José Luiz Lima, a presença do Estado foi fundamental como elo articulador dos investimentos na infraestrutura, visto que "a conjuntura internacional acenava com a perspectiva de expansão das empresas multinacionais em direção às economias de industrialização tardia, o que abria horizontes extremamente favoráveis de negociação e atração de investimentos diretos em indústrias de bens de consumo duráveis e de bens de produção". ${ }^{29}$

Dentre os instrumentos de estímulo do governo para a entrada de indústrias estrangeiras no país, o mais relevante foi a Instrução n ${ }^{\circ} 113$ da Sumoc, que fomentou a abertura do mercado e, consequentemente, elevou a participação da indústria de bens de capital na produção da economia nacional como um todo, além de provocar alteração na composição dos atores atuantes no setor. Conforme o inventário realizado por Venilton Tadini sobre a estrutura industrial brasileira, o setor de bens de capital que representava 5\% do valor da produção bruta da indústria de transformação em 1949 alcançou aproximadamente 10\% em 1959. Por outro lado, em relação à origem do capital das empresas, se no início do período 75\% das empresas eram compostas majoritariamente por capital nacional, em 1961 essa participação caiu para 61\%. ${ }^{30}$ A tendência seria ainda mais acentuada em setores mais modernos, pois essas empresas nacionais se concentravam basicamente na produção de equipamentos de menor complexidade tecnológica. ${ }^{31}$ Bens de capital do setor elétrico sob encomenda, como turbinas e geradores, por exemplo, caso precisassem adequar a produção aos aspectos específicos de cada projeto, podiam levar anos na sua produção, o que exigia uma estrutura financeira (e tecnológica) que não estava disponível para os grupos privados nacionais.

Com espaço aberto para atuação no mercado brasileiro, foi possível observar uma tendência de estabelecimento de fábricas estrangeiras do setor elétrico no período. Conforme dados da Associação Brasileira para o Desen-

\footnotetext{
também: LESSA, Carlos. Quinze anos de política econômica. São Paulo: Brasiliense, 1975 e LAGO, Luís Corrêa do et al. A indústria brasileira de bens de capital. Rio de Janeiro: IBRE/FGV, 1979, p. 100.

${ }^{29}$ LIMA, José Luiz. Políticas de governo e desenvolvimento do setor de energia elétrica: do Código das Águas à crise dos anos 80 - 1934-1984. Rio de Janeiro; Memória da Eletricidade, 1995, p. 76.

${ }^{30}$ TADINI, Venilton. $O$ setor de bens de capital sob encomenda: análise do desenvolvimento recente (1974/83). São Paulo, IPE/USP, 1986, p. 24-26. Conferir também LAGO, Luiza Aranha Corrêa do et al. $A$ indústria brasileira de bens de capital. Rio de Janeiro: IBRE/FGV, 1979, p. 113.

${ }^{31}$ Leff afirma que metade das firmas que permitiram a diversificação da indústria de bens de capital no Brasil, com "as linhas de produtos mais complexos", eram subsidiárias de empresas estrangeiras. LEFF, Nathaniel. The Brazilian capital goods industry, 1929-1964. Cambridge: Harvard University Press, 1968, p. 24.
} 
volvimento da Indústria de Base - ABDIB, as empresas instaladas no período, ou que implantaram plantas para a produção de bens de capital, foram: Sade - Sul Americana de Engenharia S/A (Itália), em 1953; Ibrave - I.B. Válvulas e Equipamentos Ltda. (EUA), em 1954; CBC Indústrias Pesadas S/A. (Japão), em 1955; Mecânica Pesada S/A., do grupo Schneider (França), em 1955; IND. EL. Brown Boveri S/A. (Suíça), em 1957; Coemsa Eletromecânica S/A (Itália), em 1960; General Eletric (EUA), em 1962; e a Siemens (Alemanha), em 1963. ${ }^{32}$

Nesse sentido, se até meados da década de 1950 o país dependia essencialmente de equipamentos importados para atender o crescimento da geração de energia demandada, no início dos anos 1960, com a chegada das multinacionais, é possível afirmar que já existia uma produção desenvolvida no país disponível para os novos empreendimentos hidrelétricos em construção (tabela 1). Cumpria-se, assim, a meta número 29 do Plano de Metas, de produzir no país equipamentos como turbinas hidráulicas, geradores, transformadores e motores com potência acima de 20 HP.

\footnotetext{
32 TADINI, Venilton. O setor de bens de capital sob encomenda: análise do desenvolvimento recente (1974/83). São Paulo, IPE/USP, 1986, p. 131-133. A General Electric e a Siemens já produziam no país desde a década de 1920, mas com plantas voltadas para o atendimento de pequenas dimensões ou de bens de consumo, como aparelhos eletrodomésticos. Com as fábricas da GE em Campinas e da Siemens em São Paulo, as empresas começaram a disponibilizar produtos de maior complexidade, tanto para o setor de transporte (como as composições de trens também fabricadas pela GE) quanto hidrogeradores e transformadores de maiores potências. CACHAPUZ, Paulo Brandi (coord). Panorama do setor de energia elétrica no Brasil. Rio de Janeiro: Centro de Memória da Eletricidade no Brasil, 2006, p. 252.
} 
Tabela 1

Importação como porcentagem do consumo doméstico, 1949-1961 ${ }^{33}$

\begin{tabular}{|c|c|c|c|}
\hline Setor & $\mathbf{1 9 4 9}$ & $\mathbf{1 9 5 8}$ & $\mathbf{1 9 6 1}$ \\
\hline Metalúrgico & 22 & 12 & 12 \\
\hline Material elétrico & 45 & 13 & 17 \\
\hline Equipamento de transporte & 57 & 31 & 19 \\
\hline Químico e farmacêutico & 29 & 20 & 17 \\
\hline Papel & 10 & 4 & 4 \\
\hline Produtos de borracha & 10 & 5 & 7 \\
\hline Têxteis & 6 & 1 & 1 \\
\hline Produtos mecânicos & 64 & 42 & 46 \\
\hline
\end{tabular}

Fonte: LEFF, Nathaniel. The Brazilian capital goods industry, 1929-1964.

Cambridge: Harvard University Press, 1968.

Luiz A. Corrêa do Lago et al., atestando o aumento da participação relativa da produção interna no atendimento do mercado doméstico, informa que, entre 1958 e 1961, o crescimento das importações em dólares cresceu 11,7\%, enquanto o crescimento da produção real interna foi de 93,4\%. ${ }^{34}$ Isto é, o Plano de Metas permitiu, tanto por meio de instrumentos cambiais, da Sumoc $\mathrm{n}^{\mathrm{o}} 113$, como também por tornar o Estado um importante demandante, ${ }^{35}$ esse florescimento da indústria pesada de materiais elétricos na década de $1960 .{ }^{36}$

33 Os dados de Leff são do consumo geral de bens de cada setor. No que diz respeito ao setor elétrico, se levarmos em conta somente os dados para o consumo de bens de capital do setor elétrico, a média de importação para os primeiros anos da década de 1960 fica entre 30 e 40\%. LAGO, Luiz Aranha Corrêa do et al. A indústria brasileira de bens de capital. Rio de Janeiro: IBRE/FGV, 1979, p. 133.

${ }^{34}$ LAGO, Luiz Aranha Corrêa do et al. A indústria brasileira de bens de capital. Rio de Janeiro: IBRE/ FGV, 1979, p. 110.

${ }^{35}$ LEFF, Nathaniel. The Brazilian capital goods industry, 1929-1964. Cambridge: Harvard University Press, 1968, p. 22 e 104.

${ }^{36}$ Como afirma Fabio Erber: "entre o pós-guerra e 1960, a participação do setor público na formação bruta de capital no país subiu de 22\% para 55\%, o que dá uma ideia da demanda 
Vale ressaltar que a nacionalização da produção, por meio da instalação de indústrias de bens de capital no país não significava a nacionalização do controle das empresas. O desenvolvimento do setor, apoiado pelo Estado, esteve fundado no estímulo da entrada de multinacionais no mercado brasileiro. A criação do BNDE em 1952 (com uma ação tímida até o Plano de Metas) e da Eletrobras, na década seguinte, representam essa nova estrutura institucional de atuação do governo na economia. Se o BNDE seria o instrumento de captação e gestão dos recursos para os projetos elétricos - tendo controle do Fundo Federal de Eletrificação -, a Eletrobras posteriormente assumiria a responsabilidade de planejamento e de integração do setor elétrico nacional: a nova divisão do mercado brasileiro permitiria que a aprovação da Eletrobras fosse quase natural nos anos $1960 .{ }^{37}$ Assim, nas duas décadas seguintes, com o cenário de expansão econômica no período do segundo governo militar, os investimentos do Estado em infraestrutura seriam ainda mais ampliados, tanto na construção de usinas como na interligação dos sistemas, o que aquecia o mercado para equipamentos elétricos. Dessa forma, a Eletrobras era o principal consumidor de equipamentos elétricos no país, representando cerca de 50\% de toda a elevação da capacidade instalada entre $1962-1980 . .^{38}$

estatal por equipamento". ERBER, Fabio Stefano. Absorção e criação de tecnologias na indústria de bens de capital. Rio de Janeiro: Finep, 1974, p. 18.

${ }^{37}$ O presidente Jânio Quadros assinou, em 26 de abril de 1961, a Lei 3890-A, que autorizava a criação da Eletrobras. O texto lei foi aprovado com várias emendas, com recuo completo da possibilidade de atuação da empresa no setor de produção de equipamentos elétricos pesados.

${ }^{38}$ Dados gerais obtidos pelo Banco de Informações de Geração (BIG) da Aneel. Disponível em: $<$ www.aneel.gov.br/aplicacoes/capacidadebrasil/GeracaoTipoFase.asp?tipo=1 $\&$ fase=3>. Acesso em: $1^{\circ}$ set. 2014. 
Tabela 2

Capacidade instalada no Brasil (1962-1980) ${ }^{39}$

\begin{tabular}{|c|c|}
\hline Ano & Capacidade Instalada em MW \\
\hline 1962 & 5.729 \\
\hline 1965 & 7.411 \\
\hline 1970 & 11.233 \\
\hline 1973 & 15.354 \\
\hline 1976 & 20.827 \\
\hline 1979 & 27.970 \\
\hline 1980 & 31.147 \\
\hline
\end{tabular}

Fonte: IBGE Anuário Estatístico do Brasil.

Assim, na década de 1960 estava completo o novo modelo de desenvolvimento do setor elétrico nacional que perduraria nas próximas duas décadas. O governo, mediante empresas públicas federais e estaduais, assumia o investimento na infraestrutura, com a construção de hidrelétricas. O capital privado internacional, antes presente na construção do setor, tanto na prestação do serviço como na exportação de equipamentos para o Brasil, buscava, nesse momento, internalizar a produção, garantindo suas fatias de mercado e se valendo dos estímulos do Estado seja para estabelecer empresas no país, seja como demandante de produtos. Ao capital nacional restavam as bordas do mercado, ou por meio de indústrias que passariam a fornecer insumos para as multinacionais recém-instaladas ou para atendimento de bens industriais de menor complexidade tecnológica.

Conforme dados de Eduardo Stracham, apresentados no Anexo I, o índice de "nacionalização" de turbinas e hidrogeradores - isto é, de produção dentro do país, especialmente por meio de multinacionais -, alcançou a mé-

\footnotetext{
39 No Brasil é expressivo o predomínio do modelo hidrelétrico: a potência instalada de usinas de energia elétrica hidráulica em 1960 representava 75,8\% e de térmicas 14,2\%; em 1970, 78,5\% de usinas hidráulicas e 11,5\% de usinas térmicas; e, em 1980, 86,7\% de usinas hidráulicas e 13,3\% de usinas térmicas. Cf. IBGE. Estatísticas históricas do Brasil: séries econômicas, demográficas e sociais de 1550 a 1988. v. 3. Séries Estatísticas. Retrospectivas. Rio de Janeiro: IBGE, 1990.
} 
dia aproximada de 60\% entre os anos de 1969 e 1985. Venilton Tadini chegou a afirmar que, em 1985, esse índice já alcançava 90\%. ${ }^{40} \mathrm{Na}$ próxima seção, apresentamos o perfil do consumo da Eletrobras no período em destaque, avaliando como a empresa reagiu aos programas governamentais e às conjunturas econômicas para garantir a expansão de suas hidrelétricas.

\section{A indústria de equipamentos elétricos sob o viés da demanda: análise da Eletrobras}

Apresentamos a seguir o inventário dos bens de capital sob encomenda para o setor elétrico, com destaque para as turbinas, os geradores e os transformadores, que compuseram as usinas Eletrobras construídas entre 1960 e 1980. A investigação foi estabelecida considerando as cinco subsidiárias da empresa, isto é, a Chesf, Furnas, Eletrosul, Eletronorte e Eletrobras Amazonas. ${ }^{41}$ Para o artigo, todavia, consideramos apenas as usinas que foram construídas no período de 1960 a 1980 (conferir Anexo II), inclusive aquelas usinas que começaram a ser construídas antes da formação da Eletrobras, mas que foram posteriormente integradas ao sistema. Por outro lado, a Eletrosul e a Eletrobras Amazonas, cujas hidrelétricas foram construídas somente depois de 1980, não serão examinadas neste artigo. ${ }^{42}$

Entre o início dos anos 1960 e o final dos anos 1970 é possível marcar fundamentalmente três grandes fases de negociações empreendidas entre a Eletrobras e seus fornecedores de materiais elétricos para as usinas em construção: o início dos anos 1960 herda a estrutura deixada pelo Plano de Metas com a chegada de multinacionais que passaram a participar do fornecimento de equipamentos por meio da produção desenvolvida em território nacional.

\footnotetext{
${ }^{40}$ TADINI, Venilton. $O$ setor de bens de capital sob encomenda: análise do desenvolvimento recente (1974/83). São Paulo, IPE/USP: 1986, p. 83.

${ }^{41}$ Para a pesquisa completa, conferir a dissertação: SASSE, Carla Muller. Capital estrangeiro e energia elétrica no Brasil: estudo sobre as empresas fornecedoras de equipamentos para o setor elétrico. Dissertação de mestrado - FFLCH/USP, São Paulo, 2015.

42 O inventário de geração total da Eletrobras inclui também usinas térmicas e nucleares: a Companhia de Geração Térmica de Energia Elétrica - Eletrobras CGTE e a Eletrobras Eletronuclear. Podemos ainda elencar outras empresas controladas pela holding, como o Centro de Pesquisa em Energia Elétrica (Eletrobras Cepel) e a Eletrobras Participações (Eletrobras Eletropar). Adicionalmente, na área de distribuição de energia, a empresa atua com outras subsidiárias, a Eletrobras Amazonas Energia, Eletrobras Distribuição Acre, Eletrobras Distribuição Roraima, Eletrobras Distribuição Rondônia, Eletrobras Distribuição Piauí e Eletrobras Distribuição Alagoas. Para obter informações, conferir dados institucionais Eletrobras. Disponível em: <www. eletrobras.com.br>. Acesso em: 22 jun. 2013.
} 
O período entre 1968 e 1973, por outro lado, depois dos ajustes econômicos do Paeg, impôs ao governo a necessidade de buscar novas fontes de recursos para financiar a construção das hidrelétricas. Assim, valendo-se de empréstimos no exterior, os suppliers credits, as compras de equipamentos ficariam cada vez mais condicionadas pelos credores à aquisição dos materiais via importações. Finalmente, com o II PND, o governo militar buscou retomar a aceleração do processo de industrialização, incentivando novamente a ideia de que os fornecedores dos grandes projetos do Estado produzissem dentro do país. Vale reforçar, esses vinte anos foram decisivos para a expansão da potência elétrica instalada no país, necessária para acompanhar as elevadas taxas de crescimento da economia. E, ainda, a Eletrobras foi agente decisivo nessa ampliação da oferta de energia elétrica. Portanto, tornou-se a maior consumidora individual de equipamentos elétricos do país.

No período até 1968, o setor de bens de capital sustentou-se perante a capacidade instalada durante o Plano de Metas, com uma política que representava um "desdobramento das tentativas de substituição de importações" pretéritas. ${ }^{43}$ Com um período recessivo, inflacionário e de baixo crescimento até 1964, e de ajustes até 1968, os investimentos públicos foram mais tímidos e, consequentemente, os resultados do setor de bens de capital também. A criação da Comissão de Desenvolvimento Industrial em 1964 foi uma mudança digna de nota, no entanto, diante da baixa capacidade financeira, suas atividades repercutiriam mais fortemente a partir do milagre econômico.

Os empreendimentos hidrelétricos do período, das subsidiárias Chesf e Furnas, davam continuidade aos projetos já definidos no Plano de Metas. A Chesf, que representara a primeira experiência de empresa estatal no setor elétrico, na década de 1940, colocou sua primeira usina em operação em 1954, Paulo Afonso (ainda do período anterior da pesquisa). Assim, iniciamos a análise do inventário com a Usina Hidrelétrica de Araras, cujo processo de construção ocorreu entre 1956 e 1967. A usina localizada na cidade de Reriutaba (CE) possui dois geradores e duas turbinas, com potência instalada de 4000 kW. Com relação aos equipamentos da usina, as duas turbinas foram fornecidas pela empresa alemã Voith - Heidenhein e os geradores pela multinacional Brown Boveri, equipamentos todos fabricados no Brasil. ${ }^{44}$

\footnotetext{
${ }^{45}$ LAGO, Luiz Aranha Corrêa do et al. A indústria brasileira de bens de capital. Rio de Janeiro: IBRE/ FGV, 1979, p.132.

${ }^{44}$ Informações sobre a participação das indústrias de bens de capital na construção dos empreendimentos hidrelétricos: Voith e Bardella nas obras de Três Marias. O Estado de S.Paulo. São
} 
A Usina de Furnas, por outro lado, a primeira na constituição do Sistema Furnas, com a obra realizada entre 1958 e 1963, em Minas Gerais, atuava com uma potência nominal total de 375 MW. A construção da usina foi um marco no sistema elétrico nacional. Contornar a crise energética dos anos 1950 era missão dessa primeira usina de grande porte construída pelo governo na região Sudeste e que daria origem ao importante sistema de Furnas. Ao entrar em operação, a usina permitiu que o sistema das empresas privadas Light e CPFL (da AFEP) pudessem se preocupar mais com a distribuição de energia - aquilo que Nivalde Castro chamou de "pacto de clivagem". A Usina de Furnas alcançou sua potência máxima em 1974, com oito turbinas geradoras de $152 \mathrm{MW}$, operando com a capacidade final de 1.216 MW. O fornecimento das turbinas ocorreu da seguinte forma: sete foram fornecidas pelo fabricante Nohab da Suécia e uma pela empresa Bardella do Brasil. Três fabricantes foram responsáveis pelo fornecimento dos geradores: seis foram fornecidos pela Siemens da Alemanha, um pela CGE do Canadá e um pela MEP do Brasil. Os transformadores foram fornecidos pela americana GE e pela Jeumont Schneider da França. ${ }^{45}$

A Usina de Funil, também do sistema de Furnas, foi construída entre 1961 e 1969, em Resende, no estado do Rio de Janeiro, e opera com três unidades geradoras com potência nominal total de $375 \mathrm{MW}$. As turbinas do tipo Francis foram fornecidas pelo fabricante italiano Ansaldo San Giorgio, os geradores pela Gesa e os transformadores pelo fabricante GE. ${ }^{46}$

No Rio Grande, bacia das principais usinas do sistema de Furnas, entre 1963 e 1969, foi construída a Usina de Luiz C. B. Carvalho, conhecida como "Estreito". Situada no município de Pedregulho, no norte do estado de São Paulo, opera com seis unidades geradoras e possui potência nominal de 175 MW. Suas turbinas foram fornecidas pelo consórcio Voith entre Brasil e Alemanha. Os geradores foram supridos pelo fabricante Asea e os transformadores pelos fabricantes Jeumont, ACEC e COEMSA. A usina representou um marco na construção nacional devido à participação substancial de fa-

Paulo. 27 jul. 1960. Indústria Produtos e Processos, p. 18.

45 Sistemas Furnas de Geração e Distribuição/Eletrobras. Disponível em: <http://eletrobras.com. br>. Acesso em: em 8 out. 2013.

${ }^{46}$ Sistemas Furnas de Geração e Distribuição/Eletrobras. Disponível em: <http://eletrobras.com. br>. Acesso em: 8 out. 2013. 
bricantes e empreiteiros brasileiros e do cumprimento rigoroso do cronograma do projeto. ${ }^{47}$

No sistema de Furnas, duas outras hidrelétricas situadas no rio Grande seriam construídas já na década seguinte, mas ainda bastante influenciadas por esse ambiente pré-1968: Marimbondo e Porto Colômbia. A Usina de Marimbondo, construída de 1971 a 1975, entre as cidades de Icém, em São Paulo, e de Fronteira, em Minas Gerais, apresenta potência nominal de $180 \mathrm{MW}$ com oito unidades geradoras. As turbinas da casa de força foram fornecidas por um consórcio formado pelas empresas Voith, Neyrpic, Creusoti-Loire e MEP. Os geradores foram fabricados pela Asea e os transformadores pela Tusa. Marimbondo tornou-se a segunda maior usina em potência instalada no sistema de Furnas. As linhas de transmissão em 500 kV, que integram a usina ao sistema, foram as primeiras construídas no Brasil e também a operar na América Latina, o que caracterizou, definitivamente, o total domínio de firmas brasileiras nos campos de projeto, fabricação e construção de empreendimentos ligados ao setor de energia elétrica. ${ }^{48}$ Por fim, a Usina de Porto Colômbia foi construída entre 1970 e 1973, localizada entre os municípios de Planura, em Minas Gerais, e de Guaíra, em São Paulo, e opera com potência nominal de $80 \mathrm{MW}$ com quatro unidades geradoras. As turbinas da casa de força foram fornecidas pelas empresas Nohab e Bardella. Os geradores foram fabricados pela Asea e os transformadores pela ABB. ${ }^{49}$

Em suma, com a chegada das multinacionais no país, o fornecimento de bens de capital dos projetos hidrelétricos brasileiros pode superar o modelo dominante nas décadas anteriores, nos quais prevaleciam recursos financeiros internacionais, como do Banco Mundial e do Eximbank, e os equipamentos que compunham as usinas eram na essência importados. Somente os equipamentos menos sofisticados restavam para a concorrência das empresas atuantes no mercado interno.

Essa tendência de maior presença de componentes produzidos no país nos projetos hidrelétricos, todavia, seria atenuada entre 1968 e 1973. Conforme Lago descreve, esse novo período marcou mudanças fiscais que facilitaram a importação de equipamentos, como a isenção de impostos esta-

\footnotetext{
${ }^{47}$ Sistemas Furnas de Geração e Distribuição/Eletrobras. Disponível em: <http://eletrobras.com. br>. Acesso em: 8 out. 2013.

${ }^{48}$ Sistemas Furnas de Geração e Distribuição/Eletrobras. Disponível em: <http://eletrobras.com. br>. Acesso em: 8 out. 2013.

${ }^{49}$ Sistemas Furnas de Geração e Distribuição/Eletrobras. Disponível em: <http://eletrobras.com. br>. Acesso em: 10 out. 2013.
} 
belecida pela Comissão de Desenvolvimento Industrial. Por outro lado, no exterior cresceram as possibilidades de crédito, que apoiaram a expansão dos projetos hidrelétricos, mas, como contrapartida, exigiram a aquisição de bens dos fornecedores externos (os suppliers' credits). ${ }^{50}$

A Usina Boa Esperança, de propriedade da Cohebe, foi construída entre 1964 e 1970, situando-se no município de Guadalupe (PI). A usina foi transferida para a Chesf em 1968, por dificuldades na realização projeto de construção, o que ilustra como as condicionalidades dos empréstimos adquiridos no exterior definiam a aquisição dos equipamentos. Atualmente a usina conta com quatro unidades geradoras de energia, duas destas entraram em operação durante a década de 1970 e as demais passaram a funcionar na década de 1990. O governo brasileiro buscou recursos estrangeiros para obter o financiamento necessário para a conclusão da obra. ${ }^{51}$ As comportas de aço e o respectivo sistema de acionamento foram encomendados da Ishikawajima do Brasil, subsidiária da empresa japonesa. As turbinas foram adquiridas de uma empresa norte-americana e os geradores de uma empresa brasileira. ${ }^{52}$ Apesar de não confirmarmos os fornecedores de equipamentos, estes foram importados.

A Usina Apolônio Sales, também do sistema Chesf e do represamento de Moxotó - da bacia do rio São Francisco -, foi construída entre 1971 e 1977, localizada no município de Delmiro Gouveia (AL). Sua infraestrutura de equipamentos é formada por quatro unidades geradoras e quatro turbinas com potência instalada de $400.000 \mathrm{~kW}$. A construção da usina era parte de grandes empreendimentos hidrelétricos previstos para a década de 1970, como uma resposta técnica e de planejamento do governo militar com o propósito de fazer frente à expansão da demanda por energia elétrica em uma fase de grande crescimento econômico. Entre 1969 e 1970, a demanda por energia cresceu à taxa de 12\% e as estimativas da Eletrobras apontavam a permanência de incrementos das taxas anuais conforme destaca a matéria publicada no jornal $O$ Estado de S.Paulo.

Para atender a esta previsível demanda futura terá a Eletrobras de adicionar mais 5.800 mil kW de potência instalada entre 1971 e 1974, período em que deverão ser iniciados

\footnotetext{
${ }^{50}$ LAGO, Luiz Aranha Corrêa. A retomada do crescimento e as distorções do "milagre": 1967-1973. In: ABREU, M. de P. (org.). A ordem do progresso. Cem anos de política econômica republicana, 1889-1989. Rio de Janeiro: Campus, 1990, p. 244.

${ }^{51}$ 8,9 milhões de dólares para usina. O Estado de S.Paulo, 29 out. 1965. Geral, p. 34.

${ }^{52}$ COHEBE cumpre o seu objetivo. O Estado de S.Paulo, 25 fev. 1966. Geral, p. 5.
} 
investimentos para agregar mais 13 milhões de $\mathrm{kW}$ para entrada em operação entre 1975/1979. Para realização dessas obras e mais as correspondentes às linhas de transmissão e distribuição serão necessários investimentos vultosos da ordem de Cr\$ 4,5 bilhões anuais, ou seja, o equivalente a 1 bilhão de dólares para os quais a Eletrobras concorrerá com $40 \%$ de recursos próprios. ${ }^{53}$

Se o controle dos recursos para a realização dos investimentos pela estatal indicava possibilidade de certa independência no que diz respeito à escolha dos equipamentos, o período demonstrava como essa autonomia vinha sendo reduzida. Afinal, fora os 40\% de recursos próprios, o financiamento das obras da Usina de Apolônio Sales dependeu de expressiva contribuição de financiamento direto do Banco Interamericano de Desenvolvimento (BID), e essa participação pode ser evidenciada nos diversos editais para convocação de concorrência para compra de equipamentos:

A Chesf realizará uma licitação internacional (...) para a Usina de Moxotó. Para pagamento dos equipamentos mencionados espera contar a Chesf com os recursos do Banco Interamericano de Desenvolvimento através de financiamento ora em fase de negociação. Somente poderão participar da licitação internacional os fabricantes brasileiros e os fabricantes estrangeiros que sejam nacionais de qualquer dos países-membros do Banco Interamericano de Desenvolvimento. ${ }^{54}$

O exemplo destacado corrobora a compreensão da coesão entre a barganha do capital que proporciona o desenvolvimento e as demais forças que se associam e logram destaque junto a ele. Os editais, ademais, apresentavam especificações que praticamente definiam os fornecedores. Uma breve análise da composição dos países-membro do BID no início da década de 1970 permite inferir a origem daquelas empresas que teriam condições de atender às demandas por equipamentos que se colocavam. ${ }^{55}$ Evidenciamos as condições expostas na consolidação do fornecimento dos equipamentos para a Usina Apolônio Sales. A infraestrutura principal de geração, por meio de geradores e turbinas, foi fornecida pelo consórcio da GE formado pelas seguintes companhias: General Eletric do Brasil (líder) e as empresas cana-

\footnotetext{
53 Eletrobras reduz juros dos créditos. O Estado de S.Paulo, 20 jan. 1971. Geral, p. 22.

${ }^{54}$ Pré-qualificação de fabricantes, Usina de Moxotó. O Estado de S.Paulo, 26 out. 1971. Geral, p. 8.

55 De acordo com dados do BID, até a primeira metade da década de 1970 a composição se limitava aos países da América Latina, Estados Unidos e Canadá (que aderiu ao sistema em 1972).
} 
denses Canadian General Electric Company Limited e Dominion Engineering Works Limited. ${ }^{56}$

Finalmente, a Usina de Paulo Afonso III, integrante do complexo hidrelétrico de Paulo Afonso, foi construída entre 1967 e 1971, com infraestrutura de geração composta por quatro geradores e quatro turbinas que perfazem a capacidade atual de potência instalada de $794.200 \mathrm{~kW}$. Com relação aos equipamentos da casa de forças, os quatro geradores da usina foram fornecidos pela Siemens, considerados os maiores já produzidos no Brasil até aquele momento. É preciso lembrar que, desde 1963, a empresa alemã operava em sua unidade fabril no bairro da Lapa, em São Paulo, produzindo diversos componentes e hidrogeradores. ${ }^{57}$ As quatro turbinas, por outro lado, foram fabricadas pela Voith Brasil, em parceria com a empresa suíça Escher Wyss AG. ${ }^{58}$

O debate narrado pelo jornal $O$ Estado de S.Paulo e as experiências de busca de recursos no BID ilustram a reversão da tendência de autossuficiência que a indústria de encomendas para o setor elétrico vinha alcançando. Especialmente entre os anos 1968-1973, apesar da estrutura industrial nacional ter capacidade de atender parte significativa da demanda de equipamentos, as condições de financiamento do país impuseram condicionantes para a busca de crédito internacional. Por isso, apesar do crescimento da produção interna de bens de capital, os suppliers' credits, que condicionavam o crédito à aquisição de equipamento importado, e a isenção de impostos de importação, geraram um viés que favoreceu as importações. ${ }^{59}$

Finalmente, com o II Plano Nacional de Desenvolvimento (II PND) retomou-se um projeto de priorização da produção nacional. Com foco na conflagração da turbulência internacional, gerada pelo primeiro choque do

\footnotetext{
${ }^{56}$ Dados obtidos na apresentação do consórcio GE para prospectar sua participação no fornecimento dos equipamentos para o empreendimento de Itaipu. Naquela ocasião foi apresentado o memorial técnico do fornecimento de equipamentos presentes em outros empreendimentos internacionais e nacionais, entre eles Moxotó. Usina de Itaipu: apresentação pelo Consórcio GE à Diretoria de Itaipu Binacional em Porto Presidente Strossner. O Estado de S.Paulo, 4 nov. 1976. Geral, p. 27.

${ }^{57}$ Paulo Afonso IV vai receber da Siemens os 5 maiores geradores já fabricados no Brasil. $O$ Estado de S.Paulo $1^{\circ}$ jul. 1976. Geral, p. 10.

${ }^{58}$ A Voith fabricou também as comportas e a máquina limpa grade. Com Paulo Afonso III a Chesf põe em operação o maior conjunto hidrelétrico do Brasil, na atualidade. O Estado de S.Paulo, 30 nov. 1971. Geral, p. 17.

${ }^{59}$ LAGO, Luiz Aranha Corrêa do et al. A indústria brasileira de bens de capital. Rio de Janeiro: IBRE/ FGV, 1979, p. 140-5 e TADINI, Venilton. O setor de bens de capital sob encomenda: análise do desenvolvimento recente (1974/83). São Paulo, IPE/USP, 1986, p.28.
} 
petróleo de 1973, o governo Geisel elaborou um programa de desenvolvimento para o período de 1975-1979 que, de acordo com Lessa, era uma nova estratégia de desenvolvimento. Representada pela articulação de um novo padrão de industrialização, com centralidade na indústria de base e no fortalecimento do tripé Estado, capital privado nacional e capital privado estrangeiro, o projeto buscaria atrair capitais externos para o financiamento do crescimento. ${ }^{60} \mathrm{O}$ II PND demandava fortes investimentos e, de acordo com Lima, "não restava alternativa às empresas estatais senão o acesso a recursos externos para sustentar o maciço bloco de investimentos previstos pelo II PND, o que suscitava nova configuração dos pactos selados entre empresa pública e os fornecedores nacionais" ${ }^{\prime 61}$. O que poderia significar, em determinados momentos, ceder às pressões do financiador estrangeiro com o "favorecimento" na aquisição dos equipamentos necessários para os empreendimentos de expansão do setor elétrico nacional.

Partindo da referida perspectiva de atuação do Estado para promover o desenvolvimento da infraestrutura elétrica e também do fortalecimento da indústria de base, surge a Comissão de Coordenação dos Núcleos de Articulação com a Indústria (CCNAI). ${ }^{62}$ A proposta de constituição desse conselho evidenciava uma tentativa de estabelecer a aproximação entre o Estado, no caso as empresas estatais responsáveis pelos empreendimentos do setor elétrico, e a indústria nacional. Essa iniciativa, no entanto, não foi pioneira, ainda na década de 1950, o Banco Nacional de Desenvolvimento Econômico já contemplava, em seu arcabouço de tarefas, essa perspectiva no Departamento Econômico e de Projetos. ${ }^{63}$ Nesse sentido, o período reforça a ideia do governo de acelerar o processo de industrialização brasileira, ainda que pressionada pelos créditos externos, mas dando maior autonomia para as empresas públicas buscarem fornecedores nacionais.

\footnotetext{
${ }^{60}$ LESSA, Carlos. A estratégia de desenvolvimento, 1974-1976 sonho e fracasso. Tese de doutorado - FEA/ UFRJ, Rio de Janeiro, 1978.

${ }^{61}$ LIMA, José Luiz. Políticas de governo e desenvolvimento do setor de energia elétrica: do Código das Águas à crise dos anos 80 - 1934-1984. Rio de Janeiro; Memória da Eletricidade, 1995, p. 117.

${ }^{62}$ O Núcleo de Articulação com a Indústria (NAI) surge com o Decreto nº 76.409 de 1975.

${ }^{63}$ O Departamento Econômico e de Projetos do BNDE tinha por atribuição a formulação de estudos relacionados a setores específicos, além de estabelecer uma análise estratégica do mercado sob um prisma macroeconômico. Estes e os grupos executivos do governo JK demonstravam dinâmica consensual em relação à proposta de incentivar o fortalecimento da indústria nacional. Para mais informação sobre a atuação dos NAIs, ver: KLEIN, Lúcia. A atuação da CCNAI na substituição de importação de bens de capital. Rio de Janeiro: Finep. Relatórios de estudos e projetos, $n^{\circ} 1 / 1983$.
} 
A Usina Hidrelétrica de Paulo Afonso IV foi construída entre 1972 e 1979. Em sua infraestrutura destacamos a casa de força composta por seis unidades geradoras e seis turbinas que totalizam a potência instalada de 2.462.400 kW. As unidades de geradores encomendadas pela Chesf foram também produzidas pela Siemens. As turbinas foram fornecidas pelo consórcio nacional constituído pelas empresas Voith S/A Máquinas e Equipamentos, BSI - Indústrias Mecânicas S/A e Bardella S/A Indústrias Mecânicas. A produção ocorreu no Brasil com índice de nacionalização de 75\%, e os recursos para a compra dos equipamentos foram obtidos por meio de financiamento da própria Eletrobras. ${ }^{64}$

Ainda compondo o sistema Chesf, outras duas usinas seriam inauguradas no período, a Usina da Pedra e a de Sobradinho. A Usina da Pedra, localizada no estado da Bahia, foi construída entre 1976 e 1978 e sua casa de força conta com uma unidade geradora fornecida pela empresa Brown Boveri e com uma turbina fornecida pela empresa francesa Neyrpic/MEP (adquirida pela Alstom em 1967) com potência instalada de 20.000 kW.65 A Usina de Sobradinho, também localizada na Bahia, foi construída entre 1973 e 1979, alcançando uma potência instalada de 1.050 .300 kW. Esse potencial é proporcionado pela infraestrutura da casa de força que opera com seis unidades geradoras e seis turbinas. Como um caso bastante particular, as seis turbinas e geradores da usina foram importadas da União Soviética. Essa particularidade se inseria num contexto de final da década de 1970, especialmente durante o governo Geisel, de uma nova linha de política externa, com maior aproximação a Moscou, conhecida como pragmatismo responsável ecumênico. Imbuído do propósito de desenvolvimento, o governo buscou aproximação técnica e comercial com os países do bloco socialista. ${ }^{66}$

A cooperação econômica entre Brasil e a União Soviética, ilustrada no caso em questão, revela a aproximação entre os interesses econômicos dos países, mesmo que estes contrariassem aqueles que eram compreendidos como os interesses nacionais que integravam o projeto do governo militar. Essa aproximação polêmica não passou em branco entre os políticos do período, inclusive com questionamentos sobre a capacidade de oferta de equipamentos elétricos pela indústria nacional.

\footnotetext{
${ }^{64}$ Informação sobre a origem dos recursos: hidrelétricas tem núcleos de apoio. O Estado de S.Paulo, 4 jun. 1976. Geral, p. 27.

${ }^{65}$ Disponível em: <http://chesf.gov.br>. Acesso em: 10 jul. 2013.

${ }^{66}$ CERVO, Amado E BUENO, Clodoaldo. História da política exterior do Brasil. Brasília: Ed. UnB, 2002.
} 
No debate com Saturnino Braga [sobre Sobradinho], o senador Passarinho contestou um aparte do representante governista Luiz Cavalcante, que se valeu de informações obtidas junto ao secretário da Indústria e Comércio de São Paulo, Osvaldo Palma, para dizer que o Brasil tem condições de produzir equipamentos para usinas hidrelétricas, embora o país continue realizando importações nessa área, como ocorreu com a usina de Sobradinho, construída com turbinas soviéticas. “Não creio - observou Passarinho - que o Brasil tenha condições para construir equipamentos deste gênero e não tenho notícia de uma única usina feita com turbinas brasileiras de grande porte." O senador oposicionista disse, ao contrário, que é possível fazer muito mais, dando oportunidade à indústria nacional, com ampliação do mercado de trabalho e sem cair na recessão. Saturnino Braga defendeu o contingenciamento das importações. ${ }^{67}$

A Usina de Itumbiara, do sistema de Furnas, foi construída entre 1974 e 1980, localizada entre os municípios de Itumbiara, em Goiás, e Araporã, em Minas Gerais. Tratava-se da maior usina do sistema. Sua casa de força opera com seis unidades geradoras com potência nominal de $347 \mathrm{MW}$. Suas turbinas foram fornecidas pela Voith da Alemanha, Bardella, BSI e Voith do Brasil. ${ }^{68}$ Os geradores foram fornecidos pelos fabricantes Gebsa do Brasil e a CGE do Canadá, e os transformadores pela empresa brasileira Tusa. ${ }^{69}$

O projeto de Itumbiara materializa os limites da atuação da indústria nacional, assim como sobre o relacionamento da indústria nacional com as esferas públicas, responsáveis pelo planejamento e operacionalização e pela demanda por equipamentos elétricos. Afinal, o responsável pelo empreendimento, o Estado, em virtude dos altos investimentos necessários, dependia de expressivos valores para financiar as obras. A obtenção desses investimentos dependia de uma composição de recursos internos e externos, e essa organização de fontes está profundamente relacionada à conjuntura econômica e política, tanto interna como externa. Assim, observamos ao longo do tempo momentos de maior ou menor independência econômica que influenciam diretamente a liberdade de escolha dos fornecedores de

\footnotetext{
${ }^{67}$ Passarinho discorda das receitas oposicionistas. O Estado de S.Paulo, 5 ago. 1980. Geral. p. 28.

${ }^{68}$ Desde 1957, a empresa brasileira Bardella estreitou seus laços com a empresa alemã Voith para produção de turbinas. Esse projeto de produção nacional de turbinas ocorreu gradativamente a partir de 1958/59 com o processo de modernização da fábrica da Bardella, em que a Voith se tornava acionista com 25\% das ações da Bardella. Mais informações em: Programa de fabricação da Bardella de 1960. O Estado de S.Paulo, 13 jan. 1960. Indústria, Produtos e Processos, p. 12.

${ }^{69}$ A contribuição de firmas brasileiras no empreendimento foi de 97\%, atingindo índices inéditos de nacionalização nesse tipo de obra. O índice de fornecimento de equipamentos principais chegou a 90\%. Sistemas Furnas de Geração e Distribuição/Eletrobras. Disponível em: <http:// eletrobras.com.br>. Acesso em: 8 out. 2013.
} 
equipamentos. Ademais, outro fator decisivo relaciona-se à vontade política e aos esforços necessários para valorização e prioridade da indústria nacional. No caso de Itumbiara, diferente dos projetos da Chesf, a "vontade" política evidenciou-se na articulação para participação do capital nacional na execução do projeto. De acordo com artigo do jornal Gazeta Mercantil, o BNDE liberou duas linhas de crédito a Furnas para financiamento da aquisição de equipamentos para a construção de Itumbiara, e essas linhas de crédito condicionavam a compra de equipamentos no mercado nacional. As cláusulas contratuais explicitavam, claramente, as demandas da empresa por meio de equipamentos já produzidos pela indústria nacional. ${ }^{70}$

Os empresários nacionais ainda mencionavam a necessidade de novos investimentos da indústria nacional para diversificação de seu portfólio de produtos. Em certo sentido, seriam atendidos pelo Banco do Brasil. Esse banco criou uma linha de crédito especial para incentivar a fabricação de equipamentos nas áreas de geração e transmissão de energia elétrica, proposta que apresentava claro viés governamental de incentivo à substituição de importações. ${ }^{71}$ As ações do governo respondiam às demandas e ao espaço de articulação política ocupado pelas associações representativas da indústria nacional. Para atender às exigências de fabricação de maior quantidade de componentes no país, os industriais elencavam regras explícitas sobre a necessidade de nacionalização dos produtos, exigindo taxa de juros favoráveis para projetos associados à participação de produtos nacionais. ${ }^{72}$

Por fim, a Eletronorte, uma subsidiária do sistema de Furnas, com sede no Distrito Federal, foi criada em 1973 e tem como escopo de suas atribuições operacionais gerar e comercializar energia elétrica para os nove estados da Amazônia Legal:73 Acre, Amapá, Amazonas, Maranhão, Mato Grosso, Pará, Rondônia, Roraima e Tocantins. Por meio do Sistema Interligado Nacional (SIN), é capaz de fornecer energia a outras regiões do país. A Usina de Curuá-Una, localizada no estado do Pará, com potência instalada de 30 MW, recebeu equipamentos produzidos no Brasil:

A primeira usina hidrelétrica da Amazônia - a Curuá-Una, no Pará - será inaugurada neste ano. O projeto está incluído na primeira ETA do Programa de Integração Nacional

\footnotetext{
${ }_{70}$ O BNDE protege o produto nacional. Gazeta Mercantil, 3 jun. 1975. p. 1 e 6.

${ }^{71}$ Banco do Brasil financia bens de capital. Gazeta Mercantil, 13 ago. 1975, p. 1.

${ }^{72}$ Furnas: nacionalização será de 80\%. Rio de Janeiro. Gazeta Mercantil, 22 set. 1975. p. 8.

${ }^{73}$ Ver dados institucionais da Eletronorte: estrutura e perfil da Eletrobras Eletronorte. Disponível em: <http://eletrobras.com.br/eletronorte>. Acesso em: 10 mar. 2014.
} 
e para ele o presidente Médici autorizou, em novembro, a liberação da verba de sete milhões e 100 mil cruzeiros. Em sua primeira fase, a usina irá operar com um hidrogerador de 12.500 KVA, produzido em Campinas pelo Departamento de Equipamento Pesado da General Eletric S.A., esta máquina está sendo instalada e será acionada por turbina tipo Kaplan, fornecida pela Bardella SA Indústrias Mecânicas. ${ }^{74}$

A Usina hidrelétrica de Tucuruí, do sistema Eletronorte, foi construída em duas fases. Apesar de ter sido inaugurada em 1984 (com obras iniciadas em 1976), a conclusão do projeto da primeira fase ocorreu somente em 1992, com a entrega do potencial instalado de 4.245 MW. A casa de força dessa fase era formada por 12 unidades geradoras e duas auxiliares. O processo de aquisição dos equipamentos da casa de força foi objeto de debate entre aqueles que defendiam o espaço de atuação da indústria nacional como um importante agente nos empreendimentos em andamento e as reais possibilidades de recursos que estavam em curso. A escassez de recursos internos para financiamento dos projetos trazia à pauta antigas questões, como as insistentes importações de equipamentos que estavam, muitas vezes, vinculadas aos financiamentos obtidos de organismos internacionais públicos e privados.

As concessionárias do setor elétrico não dispõem de recursos para investimentos (...). A denúncia foi feita no Rio, pelo diretor de importante empresa de bens de capital (...). O estranho, segundo o empresário, é que o cumprimento dos cronogramas físicos e financeiros destas obras planejadas com tanto rigor técnico sempre contemplam a indústria estrangeira. Citou o pacote das hidrelétricas de Tucuruí e Itaparica, em que a indústria brasileira tem índice de nacionalização de 75 a 100\% para importantes equipamentos, mas até agora só recebeu pequenas encomendas (...). Lembrou que empresas francesas e alemãs já produziram para as duas hidrelétricas US\$ 460 milhões (Cr\$ 53,3 bilhões) em equipamentos que estão prontos e não podem ser montados porque Tucuruí está com atraso de pelo menos seis meses, enquanto Itaparica praticamente não existe. Mas tudo já foi pago, havendo no momento outro pesado ônus; despesas de armazenagem, seguros e serviços de segurança, enquanto os produtos continuam sob a guarda das indústrias daqueles países, acrescentou. O Brasil tomou no Exterior US\$ 929 milhões para serem aplicados em Tucuruí e Itaparica. Deste montante, US\$ 460 milhões representavam os equipamentos importados (supplier scredits) e US\$ 469 milhões o empréstimo financeiro. O empresário enfatizou que o crédito vinculado foi utilizado rapidamente, com aquisições nas indústrias francesas e alemãs, o que poderia esperar em razão dos

\footnotetext{
${ }^{74}$ Amazônia vai ter hidrelétrica. O Estado de S.Paulo, 2 abr. 1972. Geral, p. 51.
} 
atrasos das obras, principalmente Itaparica. ${ }^{75}$ Os índices de nacionalização dos bens de capital, fixados pelo governo para meados de 1979, podem ser atingidos em 1977, afirmou ontem, no Rio, o diretor da Abdib - Associação Brasileira para o Desenvolvimento das Indústrias de Base - Henrique Sansom. Para que isto ocorra, entretanto, "é fundamental que o próprio governo mude a política que vem adotando até o dia de hoje, ou seja, de favorecer a importação de equipamentos e aceitar investimentos externos vinculados a bens de capital produzidos em outros países." (...) Lembrou, também, entre outras obras de grande porte, a hidrelétrica de Tucuruí que importará suas turbinas de um consórcio europeu em decorrência dos financiamentos franceses para o projeto. ${ }^{76}$

Com relação à composição final da primeira fase da Usina de Tucuruí, destacamos o seu inventário de máquinas: dois geradores fornecidos pela General Electric do Brasil S.A., ambos fabricados no Brasil e com índice de nacionalização superior a 90\% dos seus componentes, marco bastante significativo para o setor. ${ }^{77}$ Ademais, a empresa Mecânica Pesada S.A. forneceu outras quatro unidades geradoras para Tucuruí.78 A divisão dos demais equipamentos que iriam compor o conjunto das 12 unidades geradoras da primeira fase da usina ficaram sob a responsabilidade de dois grupos: o primeiro francês, liderado pela empresa Neyrtec, e o outro brasileiro, liderado pela Mecânica Pesada S.A. ${ }^{79}$ As turbinas seguiram a mesma divisão de fornecimento das 12 unidades geradoras, reforçando a hipótese de que os créditos do Banco Europeu condicionavam a compra de equipamentos franceses.

\section{Considerações finais}

Entre as décadas de 1960 e 1970 a Eletrobras foi personagem decisiva na construção de uma política de desenvolvimento da indústria de bens de capital sob encomenda para o setor elétrico brasileiro. A principal consumidora individual do país, seus projetos, planos executivos e formas de financiamento das novas hidrelétricas eram um instrumento poderoso para fomentar a produção de equipamentos elétricos. O capital estrangeiro, por

\footnotetext{
${ }_{75}$ Mesmo endividado setor elétrico faz encomendas. O Estado de S.Paulo, 18 nov. 1981. Geral, p. 24.

${ }^{76}$ ABDIB acha possível produzir 80\% dos equipamentos em 77. O Estado de S.Paulo, 5 fev. 1977. Geral, p. 23.

${ }^{77}$ Ver informe institucional de fornecimento da empresa para os grandes empreendimentos hidrelétricos em andamento: GE a energia que antecipa o futuro. Itumbiara, Salto Santiago e Tucuruí. O Estado de S.Paulo, 3 out. 1979. Geral, p. 15.

${ }^{78}$ Geradores para Tucuruí. O Estado de S.Paulo, 13 nov. 1982. Geral, p. 35.

${ }^{79}$ Banco Europeu financia equipamentos de Tucuruí. O Estado de S.Paulo, 30 out. 1982. Geral, p. 24.
} 
outro lado, se valia do processo de industrialização da periferia e dos altos índices de crescimento econômico, para abrir novos ciclos de investimento, com setores que depositavam maiores interesses do que aquelas antigas atividades, como o do fornecimento de energia elétrica.

Assim, a partir do Plano de Metas é visível a entrada de indústrias multinacionais do setor de bens de capital do setor elétrico no país, buscando garantir os mercados que antes eram supridos pelas importações. O governo federal, com políticas fiscais, cambiais e, inclusive, como consumidor, nas duas décadas seguintes, foi ator decisivo na definição de quais grupos atuariam como fornecedores de equipamentos para o setor. O objetivo deste artigo foi mostrar, com base na análise do perfil do consumo da Eletrobras entre as décadas de 1960 e 1970, como a empresa estatal teve poder para estimular a industrialização do país, inclusive, caso houvesse interesse, de criar brechas para que os grupos privados nacionais tivessem maior participação no mercado. O que se observou pela experiência do período, todavia, foi que o modelo escolhido pelo Estado brasileiro, ao estimular a entrada dos grupos internacionais no país, legou às empresas com controle nacional de capital restritas fatias do mercado, que se referem a produtos com baixa tecnologia. Assim, a passagem para os anos 1960 marca um período em que se encerrou o ciclo da participação do capital estrangeiro na atuação do setor elétrico, como prestadora de serviços, mas se abriu novas oportunidades de atuação, diante do processo de fornecimento de bens de capital para os grandes investimentos hidrelétricos do governo militar. 


\section{Anexo I}

Origem dos fornecedores de turbinas e hidrogeradores (1969 a 1986) ${ }^{80}$

\begin{tabular}{|c|c|c|c|}
\hline \multicolumn{2}{|c|}{$\begin{array}{c}\text { Turbinas: participação } \\
\text { por nacionalidade }\end{array}$} & \multicolumn{2}{c|}{$\begin{array}{c}\text { Hidrogeradores: participação } \\
\text { por nacionalidade }\end{array}$} \\
\hline Brasil & $58,4 \%$ & Brasil & $63,6 \%$ \\
\hline Canadá & $3,7 \%$ & Canadá & $0,7 \%$ \\
\hline EUA & $0,4 \%$ & EUA & $3,4 \%$ \\
\hline França & $9,5 \%$ & França & $5,8 \%$ \\
\hline Itália & $3,8 \%$ & Itália & $1,8 \%$ \\
\hline Japão & $6,2 \%$ & Japão & $6,2 \%$ \\
\hline Alemanha Ocidental & $9 \%$ & Alemanha Ocidental & $4,5 \%$ \\
\hline Suécia & $0,7 \%$ & Suécia & $4,9 \%$ \\
\hline Suíça & $3,3 \%$ & Suíça & $5,2 \%$ \\
\hline Tchecoslováquia & $1,1 \%$ & Tchecoslováquia & $6,3 \%$ \\
\hline URSS & $3,9 \%$ & URSS & $0,3 \%$ \\
\hline
\end{tabular}

Fonte: STRACHMAN, 1992, p. 250 e 265.

\footnotetext{
${ }^{80} \mathrm{O}$ conceito de empresa nacional no setor contempla também as subsidiárias de empresas multinacionais aqui instaladas.
} 
Carla Muller Sasse \& Alexandre Macchione Saes A Eletrobras e as empresas fornecedoras de equipamentos para o setor elétrico brasileiro (1960-1980)

Principais fornecedores de turbinas e hidrogeradores (1969 a 1986)

\begin{tabular}{|c|c|c|c|}
\hline \multicolumn{2}{|c|}{$\begin{array}{c}\text { Participação das empresas } \\
\text { nacionais no fornecimento de } \\
\text { turbinas no mercado brasileiro }\end{array}$} & $\begin{array}{c}\text { Participação das empresas nacionais } \\
\text { no fornecimento de hidrogeradores } \\
\text { no mercado brasileiro }\end{array}$ \\
\hline Voith & $60 \%$ & Brown Boveri & $44,7 \%$ \\
\hline Mecânica pesada & $31,3 \%$ & Siemens & $33,6 \%$ \\
\hline Coemsa-Ansaldo & $3,8 \%$ & Coemsa & $3,9 \%$ \\
\hline Villares & $3,6 \%$ & GE/Villares & $17,8 \%$ \\
\hline Bardella & $1,3 \%$ & Total & $100 \%$ \\
\hline Total & $100 \%$ & & \\
\hline
\end{tabular}

Fonte: STRACHMAN, 1992, p. 251 e 266. 


\section{Anexo II}

Subsidiárias Eletrobras do sistema de geração de energia - UHE - 1960 a 1980

\begin{tabular}{|c|c|c|}
\hline $\begin{array}{l}\text { Subsidiárias } \\
\text { Eletrobras }\end{array}$ & $\begin{array}{c}\text { Usinas } \\
\text { (fase de construção) }\end{array}$ & Fornecedores de Equipamentos \\
\hline \multirow{9}{*}{ Chesf } & $\begin{array}{c}\text { Araras } \\
\text { (1956/abr. 1967) }\end{array}$ & $\begin{array}{l}\text { Turbinas: Voith (Brasil) } \\
\text { Geradores: Brown Boveri (Brasil) }\end{array}$ \\
\hline & $\begin{array}{l}\text { Boa Esperança } \\
\text { (ago. } 1964 \text { / abr. 1970) }\end{array}$ & $\begin{array}{l}\text { Tubinas: EUA } \\
\text { Geradores: BR }\end{array}$ \\
\hline & $\begin{array}{c}\text { Funil } \\
(1954 / \text { ago. 1962) }\end{array}$ & $\begin{array}{l}\text { Turbinas: Riva Calzoni (Itália), Societe Forges } \\
\text { (França) Geradores: GE (EUA) }\end{array}$ \\
\hline & $\begin{array}{l}\text { Luiz Gonzaga } \\
\text { (jul. } 1979 \text { / jun. 1988) }\end{array}$ & $\begin{array}{l}\text { Turbinas: Voith (Brasil) e consórcio europeu } \\
\text { Geradores: Siemens (Brasil) e consórcio europeu }\end{array}$ \\
\hline & $\begin{array}{l}\text { Apolônio Sales } \\
\text { (jan. } 1971 \text { / abr. 1977) }\end{array}$ & $\begin{array}{c}\text { Geradores e turbinas: Consórcio entre a General } \\
\text { Eletric do Brasil (líder), Canadian General Eletric } \\
\text { CompanyLimited e Dominion Engineering Works } \\
\text { Limited }\end{array}$ \\
\hline & $\begin{array}{l}\text { Paulo Afonso III } \\
(1967 / 1971)\end{array}$ & $\begin{array}{l}\text { Turbinas: Voith (Brasil) com a EscherWyss AG. } \\
\text { Geradores: Siemens (Brasil) }\end{array}$ \\
\hline & $\begin{array}{l}\text { Paulo Afonso IV } \\
(1972 / 1979)\end{array}$ & $\begin{array}{c}\text { Turbinas: Voith, BSI Indústria Mecânicas e } \\
\text { Bardella (Brasil) } \\
\text { Geradores: Siemens (Brasil) }\end{array}$ \\
\hline & $\begin{array}{c}\text { Pedra } \\
\text { (set. 1976/nov. 1978) }\end{array}$ & $\begin{array}{l}\text { Turbina: Neyrpic/MEP (França) } \\
\text { Gerador: Brown Boveri (Suécia) }\end{array}$ \\
\hline & $\begin{array}{l}\text { Sobradinho } \\
\text { (jun. } 1973 \text { / nov. 1979) }\end{array}$ & Turbinas e geradores importados da URSS \\
\hline
\end{tabular}




\begin{tabular}{|c|c|c|}
\hline $\begin{array}{l}\text { Subsidiárias } \\
\text { Eletrobras }\end{array}$ & $\begin{array}{c}\text { Usinas } \\
\text { (fase de construção) }\end{array}$ & Fornecedores de equipamentos \\
\hline \multirow{6}{*}{ Furnas } & $\begin{array}{l}\text { Usina de Funil } \\
(1961 / 1969)\end{array}$ & $\begin{array}{c}\text { Turbinas: Ansaldo San Giorgio (Itália) } \\
\text { Geradores: Gesa (Brasil) } \\
\text { Transformadores: GE (EUA) }\end{array}$ \\
\hline & $\begin{array}{l}\text { Usina de Furnas } \\
\quad(1958 / 1963)\end{array}$ & $\begin{array}{c}\text { Turbinas: Nohab (Suécia) e Bardella (Brasil). } \\
\text { Geradores: Siemens (Alemanha), CGE (Canadá) e } \\
\text { MEP (Brasil) } \\
\text { Transformadores: GE (EUA) e Jeumont (França) }\end{array}$ \\
\hline & $\begin{array}{l}\text { Usina de Itumbiara } \\
(1974 / 1980)\end{array}$ & $\begin{array}{c}\text { Turbinas: Voith (Alemanha), Bardella (Brasil), } \\
\text { BSI (Brasil) e Voith (Brasil) } \\
\text { Geradores: Gebsa (Brasil) e CGE (Canadá) } \\
\text { Transformadores: Tusa (Brasil) }\end{array}$ \\
\hline & $\begin{array}{l}\text { Usina Luiz C. B. Carvalho } \\
\text { - Estreito } \\
(1963 / 1969)\end{array}$ & $\begin{array}{l}\text { Turbinas: Voith (Brasil e Alemanha) } \\
\text { Geradores: Asea (Brasil e Suécia) } \\
\text { Transformadores: Jeumont Schneider (França), } \\
\text { ACEC (Bélgica) e COEMSA (Brasil) }\end{array}$ \\
\hline & $\begin{array}{l}\text { Usina de Marimbondo } \\
\qquad(1971 / 1975)\end{array}$ & $\begin{array}{c}\text { Turbinas: Consórcio entre Voith (Brasil e } \\
\text { Alemanha), Neyrpic(França), Creusoti-Loire(França) } \\
\text { e MEP (Brasil) } \\
\text { Geradores: Asea (Brasil e Suécia) } \\
\text { Transformadores: Tusa (Brasil) }\end{array}$ \\
\hline & $\begin{array}{l}\text { Usina de Porto Colômbia } \\
(1970 / 1973)\end{array}$ & $\begin{array}{c}\text { Turbinas: Nohab (Suécia), Bardella (Brasil) } \\
\text { Geradores: Asea (Suécia) } \\
\text { Transformadores: ABB (Brasil) }\end{array}$ \\
\hline \multirow{3}{*}{ Eletronorte } & $\begin{array}{c}\text { Tucuruí } \\
1^{\text {a }} \text { fase }(1974-1984)\end{array}$ & $\begin{array}{l}\text { Turbinas: Consórcio europeu liderado } \\
\text { pela Neyrtec (França) } \\
\text { Geradores: GE (Brasil), Mecânica pesada (Brasil) }\end{array}$ \\
\hline & $\begin{array}{l}\text { Coaracy Nunes } \\
\text { (1975) }\end{array}$ & $\begin{array}{l}\text { Não foi possível confirmar os } \\
\text { fabricantes de equipamentos. }\end{array}$ \\
\hline & $\begin{array}{l}\text { Curuá-Una } \\
\text { (1977) }\end{array}$ & $\begin{array}{l}\text { Turbinas: Bardella (Brasil) } \\
\text { Geradores: GE (Brasil) }\end{array}$ \\
\hline
\end{tabular}

Fonte: Aneel/BIG - Banco de Informações de Geração - Elaboração própria. 


\section{Referências bibliográficas}

ALEM, Ana Cláudia \& PESSOA, Ronaldo Martins. O setor de bens de capital e o desenvolvimento econômico: Quais são os desafios? BNDES Setorial. Rio de Janeiro, n. 22, 2005.

ALMEIDA, Marcio. Wohlers. Estado e energia elétrica em São Paulo: Cesp, um estudo de caso. Dissertação de mestrado - IFCH-Unicamp, Campinas, 1980.

BASTOS, P. A construção do nacionalismo econômico de Vargas. BASTOS, P. E FONSECA, P. (org.) A era Vargas. São Paulo: Ed. Unesp, 2012.

BRANCO, Catullo. Energia elétrica e capital estrangeiro no Brasil. São Paulo: Alfa-Ômega, 1975.

CACHAPUZ, Paulo Brandi (coord.). Panorama do setor de energia elétrica no Brasil. Rio de Janeiro: Centro de Memória da Eletricidade no Brasil, 2006.

CASTRO, Nivalde. O setor de energia elétrica no Brasil: a transição da propriedade privada para a propriedade pública, 1945-1961. Dissertação de mestrado - UFRJ, Rio de Janeiro, 1985.

CERVO, A.; BUENO, C. História da política exterior do Brasil. Brasília: UnB, 2002.

CLIFTON, Judith; LANTHIER, Pierre; SCHRÖTER, Harm. Regulating and deregulating the public utilities, 1830-2010. Business History, 53 (5), 2011, p. 659-672.

ECCARD, Frederico Pinto. A importância da Eletrobras para o desenvolvimento do setor elétrico brasileiro. Rio de Janeiro: Unise/Centro Celso Furtado, 2012.

ERBER, Fabio Stefano. Absorção e criação de tecnologias na indústria de bens de capital. Rio de Janeiro: Finep, 1974.

EVANS, Peter. A tríplice aliança: as multinacionais, as estatais e o capital nacional no Desenvolvimento Dependente Brasileiro. Rio de Janeiro: Zahar, 1980.

GONÇALVES. Jr., Dorival. Reestruturação do setor elétrico brasileiro: estratégia de retomada da taxa de acumulação do capital? Dissertação de mestrado em Energia - USP, São Paulo, 2002.

HAUSMAN, William; HERTNER, Peter; WILKINS, Mira. Global electrification. Multinational enterprise and international finance in the history of Light and Power, 1878-2007. Cambridge: Cambridge University Press, 2008.

KLEIN, Lúcia. A implementação dos grandes projetos governamentais nos setores siderúrgico e hidrelétrico, 1974-79. Relatório de pesquisa, Finep, 1980.

Bens de capital e o Estado no Brasil: a implantação do programa de eletricidade. X ENCONTRO ANUAL DA ANPOCS, Campos do Jordão, 1986.

LAGO, Aranha Corrêa do et al. A indústria brasileira de bens de capital. Rio de Janeiro: IBRE/FGV, 1979.

LAGO, Luiz Aranha Corrêa do. A retomada do crescimento e as distorções do "milagre": 1967-1973. ABREU, M. de P. (org.). A ordem do progresso. Cem anos de política econômica republicana, 1889-1989. Rio de Janeiro: Campus, 1990.

LANCIOTTI, Norma. Ciclos de vida en empresas de servicios públicos. Las compañías eléctricas británicas y norteamericanas en Argentina, 1887-1950. Revista de Historia Económica - Journal of Iberian and Latin American Economic History, XXVI: 3, 2008.

. Foreign Investments in Electric Utilities: A Comparative Analysis of Belgian and American Companies in Argentina, 1890-1959, Business History Review, 82 (3), 2008.

LANCIOTTI, Norma E SAES, Alexandre. La regulación de los servicios de electricidad en Argentina y Brasil (1890 e 1962), Economia e Sociedade. 21, 2012. 
rev. hist. (São Paulo), n. 174, p. 199-234, jan.-jun., 2016 http://dx.doi.org/10.11606/issn.2316-9141.rh.2016.115466
Carla Muller Sasse \& Alexandre Macchione Saes A Eletrobras e as empresas fornecedoras de equipamentos para o setor elétrico brasileiro (1960-1980)

LEFF, Nathaniel. The Brazilian capital goods industry, 1929-1964. Cambridge: Harvard University Press, 1968.

LESSA, Carlos. Quinze anos de política econômica. São Paulo: Brasiliense, 1975. . A estratégia de desenvolvimento, 1974-1976 sonho e fracasso. Tese de doutorado, FEA/UFRJ, Rio de Janeiro, 1978.

LIMA, José Luiz. Estado e energia elétrica no Brasil. São Paulo: IPE/USP, 1984.

. Estado e desenvolvimento do setor de energia elétrica: do Código das Águas à crise dos anos 80. Rio de Janeiro: Memória da Eletricidade, 1995.

MARANHÃO, Ricardo. Capital estrangeiro e Estado na eletrificação brasileira: a Light, 1945-1957. Tese de doutoramento FFLCH/USP, São Paulo, 1993.

MARTIN, Jean-Marie. Processus d'industrialisation et développement énergétique du Brésil. Paris: Institut des Hautes Études de l'Amérique Latine, 1966.

McDOWALL, Duncan. The Light. Brazilian Traction, Light and Power Company Limited, 18991945. Toronto: University of Toronto Press, 1988.

MELLO, João Manuel Cardoso de. O capitalismo tardio. São Paulo: Brasiliense, 1982.

SAES, Alexandre $\mathcal{E}$ LOUREIRO, Felipe. What developing countries' past energy policies can tell us about energy issues today? Lessons from the expropriation of American Foreign and Power in Brazil (1959-1965). Utilities Policy, v. 29, 2014, p. 36-43.

SAES, Flávio. A grande empresa de serviços públicos na economia cafeeira. São Paulo: Hucitec, 1986.

SANTOS, M. da C. O paradoxo da situação brasileira. v. XII. São Paulo: Ciesp/Fiesp, 1962. (coleção O Pensamento da Indústria.)

SASSE, Carla Muller. Capital estrangeiro e energia elétrica no Brasil: estudo sobre as empresas fornecedoras de equipamentos para o setor elétrico. Dissertação de mestrado - FFLCH/USP, São Paulo, 2015.

SEABRA, Odette. Dos meandros dos rios nos meandros do poder. Tese de doutorado - FFLCH/ USP, São Paulo, 1987.

STRACHMAN, Eduardo. Estrutura de mercado, competitividade e políticas para as indústrias internacional e brasileira de bens de capital sob encomenda para o setor elétrico. Dissertação de mestrado - Instituto de Economia, Unicamp, Campinas, 1992.

TADINI, Venilton. $O$ setor de bens de capital sob encomenda: análise do desenvolvimento recente (1974/83). São Paulo: IPE/USP, 1986.

TAVARES, Maria da Conceição. Auge e declínio do processo de substituição de importações no Brasil. Da substituição de importações ao capitalismo financeiro. Rio de Janeiro: Zahar, 1972.

TENDLER, Judith. Electric power in Brazil: Entrepreneurship in the Public Sector. Cambridge: Harvard University Press, 1968.

WILKINS, Mira. The history of foreign investment in the United States, 1914-1945. Cambridge, MA: Harvard University Press, 2004. 